\title{
AUTOMATED ESTIMATION OF DIPLOID AND TETRAPLOID NUCLEI WITH AN ELECTRONIC PARTICLE COUNTER
}

\author{
R. J. SANTEN \\ Mental Health Research Institute, University of Michigan, \\ Ann Arbor, Mich., U.S.A. \\ Received April 6, 1965
}

\begin{abstract}
A limiting factor in the biochemical quantitation of DNA and other nuclear constituents has been the inaccuracy of the enumeration of nuclei. The hemocytometer method has been accepted as a primary standard for counting nuclei and permits the use of morphologic detail as a means of control $[8,10,17,18,21,22]$. However, predictable errors in the hemocylometer method resulting from the Poisson distribution of particles in a relatively small sample are well known to exist. In routine procedures an error of 6.5-9.9 per cent is expected to occur [14]. The hemocytometer method gives no quantitative information concerning nuclear size distribution. This paper describes and evaluates a method for counting and determining the size distribution of isolated diploid and tetraploid hepatic cell nuclei of the rat by means of an electronic particle counter. RNA and DNA values per nucleus are reported for diploid and tetraploid classes.
\end{abstract}

\section{MATERIAL AND METHODS}

Animals.-Four 7-month-old Spartan rats (Haslett, Michigan) weighing $500-525 \mathrm{~g}$ and one 12-month-old Sprague-Dawley rat weighing $315 \mathrm{~g}$ were used.

Nuclear isolation. - 2.5 g portions of liver are homogenized in 9 vol. of 1 per cent ice-cold citric acid with a ball-type glass homogenizer (Kontes Glass, Vineland, New Jersey), " using 3 passes with the large clearance " $A$ " pestle, followed by 3 passes with the " $B$ " pestle. The nuclei are filtered through 4 layers of surgical gauze and centrifuged at $800 \times g$ at $0-4{ }^{\circ} \mathrm{C}$. They are then washed 2 times with 4.5 vol. of cold 1 per cent citric acid by centrifugation at $800 \times g$ and 2 times at $600 \times g$ with 9 vol. of citric acid. The nuclear extracts are diluted to $5 \mathrm{ml}$ with 1 per cent citric acid and suspended well with a glass stirring rod, then with a Disintegrator (Albertson, N.Y. Ultrasonic Industries, Inc.).

Fractionation of nuclei into polyploid classes.- The nuclei are separated into diploid-rich and tetraploid-rich classes by the continuous gradient technique of Fal-

\footnotetext{
1 Described by Dounce.
} 
zone [8]. The sucrose gradient is generated by a proportioning pump method [6], previously described. Sucrose is pumped into a gradient tube through its sintered glass filter [8]. The nuclei are layered, and after $30.38 \mathrm{hr}$, fractions 2 (diploid rich) and 4 (tetraploid-rich) [8] are recovered from above with a blind-end polyethylene tube of small diameter with side hole perforations to minimize turbulence [1]. The fractions were delivered directly into $50 \mathrm{ml}$ graduated centrifuge tubes in a bellshaped suction jar by applying vacuum. After fractions 2 and 4 are harvested, they are each diluted to $25 \mathrm{ml}$ with 8 per cent sucrose.

Counting of nuclei with electronic particle counter.--A Model B Coulter Counter and Coulter Automatic Size Distribution Plotter (Coulter Electronics, Hialeah, Florida) are used. The Model B (4) draws a dilute suspension of particles in an electrically conducting medium through a small aperture. Each passing particle alters the conductance between two electrodes. This change is translated into a vertical pulse which is proportional to particle volume, and independent of shape [11]. By adjusting a lower threshold setting (calibrated arbitrarily from 1-100), only pulses above that threshold height will be counted. An upper threshold setting (graduated 1-100) filters out pulses over the desired height. The Size Distribution Plotter automatically locks the upper threshold setting 4 units above the lower and counts successively through 25 threshold "window" positions, such as $0-4,4-8,8-12$, etc. for a preselected time from $4-32$ seconds.

Counting with electronic counter.--A $4 \mathrm{ml}$ portion of the $25 \mathrm{ml}$ suspension of nuclei obtained from the sucrose gradient is diluted to $14 \mathrm{ml}$ with a solution similar in electrolyte content to that described by Eagle [7]. It contained (in $\mathrm{g} / \mathrm{l}$ ) $\mathrm{NaCl} 6.2$, $\mathrm{KCl} 0.36, \mathrm{NaH}_{2} \mathrm{PO}_{4} \cdot \mathrm{H}_{2} \mathrm{O} 0.13, \mathrm{NaHCO}_{3} 2.0, \mathrm{CaCl}_{2} 0.18$, and $\mathrm{MgCl}_{2} \cdot 6 \mathrm{H}_{2} \mathrm{O} 0.15$. The resulting solution is then dilufed with 0.2 volume of $\mathrm{H}_{2} \mathrm{O}$ to maintain isotonicity with the sucrose-suspended nuclei. This diluent is filtered through a medium porosity sintered glass filter. (Dilutions with isotonic saline result in low instrument counts and in hemocytometer counts which diminish rapidly with time.) All dilutions are performed immediately before counting. Instrument settings [4] of APC 1, AMP 1/4,

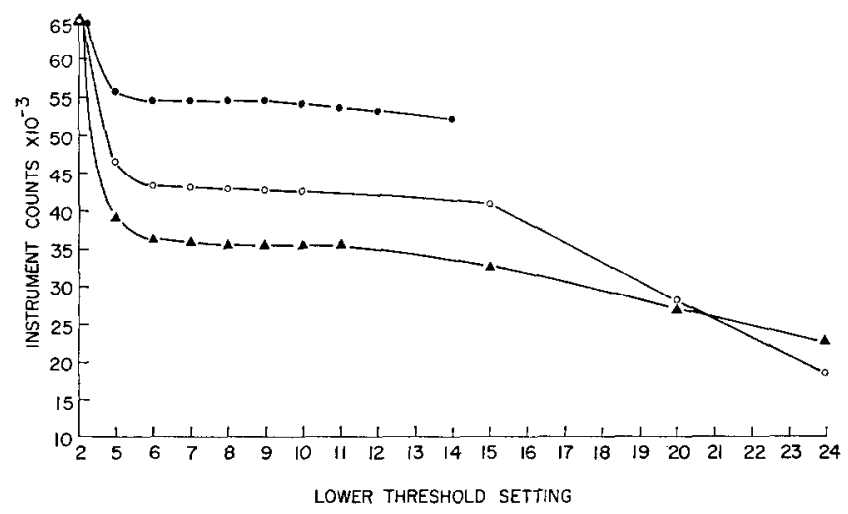

Fig. 1.-Count threshold curves. Instrument counts on three separate samples are plotted against lower threshold settings. The count plateau ranges from settings 6-12. Routine nuclei counts are taken at threshold setting 8 .

$\bullet-\bullet$, fraction $2 ; 0 \longrightarrow$, fraction $2 ; \Delta-\Lambda$, fraction 4. 
and aperture size of $100 \mu$ were found to be satisfactory for counting both fractions 2 and 4 . Coincidence corrections provided by the manufacturer are applied to all counts. Blank counts are obtained on the diluent solution before each set of determinations and are subtracted from the total counts. The sintered glass filtration reduces counts to $80-700 / 0.5 \mathrm{ml}$.

In order to determine the lower threshold settings applicable to counting both diploid and tetraploid nuclei populations, a threshold curve was plotted. A count plateau (Fig. 1) occurred consistently in the 6-12 range with a count fall-off of $2-3$ per cent in this range. The curve is similar to that reported for erythrocytes and leucocytes. A mid-plateau threshold setting of 8 was chosen for all nuclei counts. The upper threshold setting for fraction 4 was 100 , and for fraction 2 was 70 .

Nucleic acid determinations.-To the nearly $21 \mathrm{ml}$ of sample remaining after the Coulter and hemocytometer counts, an equal volume of 10 per cent trichloroacetic acid is added and the nuclei are spun at $700 \times g$ for $30 \mathrm{~min}$ at $0-4{ }^{\circ} \mathrm{C}$. The remainder of the DNA and RNA isolation procedure and ultraviolet spectrophotometric determinations are carried out as described previously for rat brain nuclei [18]. Only the single wave length $(260 \mathrm{~m} \mu)$ method for RNA was utilized.

Hemocytometer counts. - Undiluted portions of nuclei are counted in 5 separate $0.1 \mathrm{~mm}^{3}$ squares of a Spencer (bright line) hemocytometer, corrected to counts/ml, and recorded as one determination.

\section{RESULTS}

To validate the use of the Coulter Counter for enumeration of nuclei, visual counts were used as a control. Ten preparations of fraction 2 and nine of fraction 4 from five animals were counted electronically. These counts were compared with duplicate hemocytometer determinations. Table I lists the individual counts, the means, and the per cent differences between the hemocytometer and Coulter counts. The coefficient of correlation (r) was found to be 0.96 . The internal reproducibility of the Coulter Counter was determined by recording ten separate counts of 2 samples. Eight separate counts of the same sample were made with the hemocytometer. The Coulter Counter gave a standard error ranging from \pm 0.34 per cent to \pm 0.69 per cent, while the hemocytometer had a standard error of \pm 9.9 per cent. Doubling dilutions of the same sample had a standard error of \pm 1 per cent on the Coulter Counter.

To substantiate that the electronic particle counter accurately represented the diploid and tetraploid nuclei distribution in fractions 2 and 4, DNA determinations were performed. The $\mathrm{DNA} /$ nucleus in a pure diploid fraction and a pure tetraploid fraction on the basis of size distribution plots was calculated. In 10 samples of fraction 2 , the percentage of diploid nuclei (Table II) ranged from 90-93 per cent, and in fraction 4, from 37-50 per 
cent. RNA and DNA values per nucleus in these fractions are reported in Table II. Fig. 2 illustrates a typical size distribution plot for fraction 2.

Four determinations on the contents of duplicate gradient tubes with dilutions of $1 / 80,1 / 41$, and $1 / 21$, showed that the automated size distribution technique itself had a standard error of \pm 2 per cent.

TABLE I. Comparison of visual and Coulter Counts.

\begin{tabular}{|c|c|c|c|c|c|c|c|c|c|}
\hline \multirow{2}{*}{$\begin{array}{c}\begin{array}{c}\text { Frac- } \\
\text { tion }\end{array} \\
2\end{array}$} & \multicolumn{4}{|c|}{$\begin{array}{l}\text { Corrected to counts } \\
\text { per ml undiluted sample } \\
\text { Coulter Counts }-\times 10^{6}\end{array}$} & \multirow{2}{*}{$\frac{\text { Mean }}{1.394}$} & \multicolumn{2}{|c|}{$\begin{array}{l}\text { Corrected to } \\
\text { counts per ml } \\
\text { undiluted sample } \\
\text { Hemocytometer } \\
\text { Counts }-\times 10^{6}\end{array}$} & \multirow{2}{*}{ Mean } & \multirow{2}{*}{$\begin{array}{c}\begin{array}{c}\% \text { diff. } \\
\text { Hemo- } \\
\text { cyto- } \\
\text { meter vs. } \\
\text { Coulter } \\
\text { Counts }\end{array} \\
5.8\end{array}$} \\
\hline & 1.393 & 1.388 & 1.394 & 1.400 & & 1.356 & 1.270 & & \\
\hline 4 & 1.325 & 1.312 & 1.311 & 1.314 & 1.316 & 1.292 & 1.280 & 1.286 & 2.3 \\
\hline 2 & 1.217 & 1.226 & 1.215 & 1.210 & 1.217 & 1.248 & 1.363 & 1.305 & 6.7 \\
\hline 4 & 1.763 & 1.776 & 1.784 & 1.770 & 1.773 & 1.862 & 1.770 & 1.815 & 2.3 \\
\hline 2 & 1.060 & 1.058 & 1.069 & 1.058 & 1.061 & 1.174 & 1.142 & 1.158 & 8.4 \\
\hline 4 & 1.560 & 1.552 & 1.530 & 1.556 & 1.549 & 1.360 & 1.300 & 1.330 & 14.1 \\
\hline 2 & 0.671 & & & & 0.671 & 0.830 & 0.685 & 0.757 & 11.4 \\
\hline 2 & 0.748 & & & & 0.748 & 0.660 & 0.692 & 0.676 & 9.7 \\
\hline 2 & 0.614 & 0.624 & 0.607 & & 0.615 & 0.587 & 0.625 & 0.606 & 1.5 \\
\hline 4 & 0.836 & 0.838 & & & 0.837 & 0.875 & 0.932 & 0.903 & 7.3 \\
\hline 4 & 0.971 & & & & 0.971 & 0.750 & 0.850 & 0.800 & 17.7 \\
\hline 4 & 0.945 & 0.946 & 0.952 & & 0.947 & 1.010 & 1.090 & 1.050 & 9.9 \\
\hline 2 & 1.125 & & & & 1.125 & 1.130 & 1.120 & 1.125 & 0 \\
\hline 2 & 1.062 & & & & 1.062 & 1.054 & 1.001 & 1.027 & 3.3 \\
\hline 4 & 1.450 & & & & 1.450 & 1.354 & 1.343 & 1.348 & 7.0 \\
\hline 4 & 0.846 & & & & 0.846 & 0.830 & 0.850 & 0.840 & 0.6 \\
\hline 2 & 0.884 & & & & 0.884 & 0.920 & 0.972 & 0.946 & 6.6 \\
\hline 4 & 0.855 & & & & 0.855 & 0.883 & 0.844 & 0.863 & 1.1 \\
\hline \multirow[t]{2}{*}{2} & 1.176 & & & & 1.176 & 1.210 & 1.200 & 1.205 & 2.4 \\
\hline & erage & & & & 1.078 & & & 1.071 & 0.7 \\
\hline
\end{tabular}

\section{DISCUSSION}

The Coulter Electronic Particle Counter has been used successfully for counting and sizing erythrocytes $[5,14]$ and tissue culture cells $[13,15,23]$, sizing spermatozoa [19], counting leukocytes [2, 16], platelets [20], bacteria $[11,12]$, and measuring agglutination reactions [9]. It has apparently not been previously used for counting or sizing nuclei. 
The electronic counter discriminates particle volume, counting only within a critical range by means of threshold gating. This characteristic provides a criterion of purity in counting nuclei. The continuous density gradient technique separates nuclei on the basis of size. It removes contaminating particulate matter and results in a highly purified nuclear fraction for counting.

Table II. Nucleic acids in diploid and tetraploid nuclei.

\begin{tabular}{|c|c|c|c|c|c|c|c|}
\hline $\begin{array}{l}\text { Frac- } \\
\text { tion }\end{array}$ & $\begin{array}{l}\text { Number } \\
\text { of deter- } \\
\text { mina- } \\
\text { tions }\end{array}$ & $\begin{array}{l}\text { Number of } \\
\text { animals (age) }\end{array}$ & $\begin{array}{c}\text { DNA/nucleus } \\
g \times 10^{-12}\end{array}$ & $\begin{array}{c}\text { RNA/nucleus } \\
g \times 10^{-12}\end{array}$ & $\begin{array}{l}\text { RNA/ } \\
\text { DNA } \\
\text { ratio }\end{array}$ & $\begin{array}{l}\text { Per cent } \\
\text { diploid }^{a}\end{array}$ & $\begin{array}{c}\text { DNA/nucleus } \\
\text { in pure } \\
\text { ploidy classes }\end{array}$ \\
\hline 2 & 7 & 3 (7 mo.) & $7.07 \pm 0.94$ & $1.17 \pm 0.15$ & 0.169 & 91 & $6.49 \times 10^{-12} g$ \\
\hline 4 & 6 & $3(7 \mathrm{mo})$. & $10.4 \pm 1.3$ & $1.80 \pm 0.30$ & 0.173 & 43 & $13.2 \times 10^{-12} \mathrm{~g}$ \\
\hline 2 & 3 & $1(12 \mathrm{mo})$. & $6.72 \pm 0.23$ & $0.77 \pm 0.08$ & 0.115 & 91 & $6.17 \times 10^{-12} \mathrm{~g}$ \\
\hline 4 & 3 & $1(12 \mathrm{mo})$. & $10.4 \pm 0.62$ & $1.47 \pm 0.06$ & 0.141 & 37 & $12.8 \times 10^{-12} \mathrm{~g}$ \\
\hline
\end{tabular}

${ }^{a}$ On basis of Coulter Size Distribution Plotter data.

${ }^{b}$ Calculated by simultaneous equation for pure diploid and tetraploid fractions.

The results reported here for nuclei counts are comparable to those obtained in counting leukocytes and erythrocytes with the Coulter Counter $[5,16]$.

The standard error of the hemocytometer method by which nuclei have been counted routinely, has been thoroughly evaluated in relation to leukocyte counting. Berkson [3] has calculated the field error due to Poisson distribution, chamber error, and pipetting error. Without considering dilution errors, and on the basis of 1 chamber and an average total count of 500

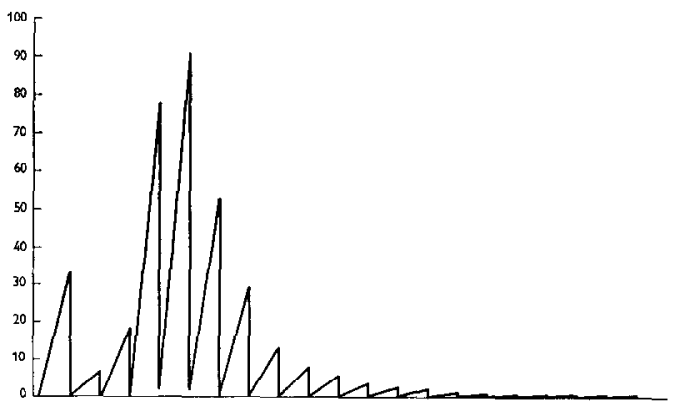

Fig. 2.- Example of a size distribution plot. This represents a typical size distribution plot for fraction 2. Threshold window 1 (thresholds $0-4$ ) is seldom recorded because it consists of counts of small particle noise. Window 2 (thresholds $4-8$ ) also represents small particle noise and is gated out in routine counts (see text). In the remaining windows, the vertical lines are proportional to the number of counts in individual threshold windows. Windows 2-21 are represented above. 
nuclei, the expected error is \pm 6.5 per cent. The main source of error is the small sample actually counted. This factor is eliminated by the electronic counter which counts $50-150$ times as many nuclei per determination.

The Coulter Size Distribution Plotter automatically records the particle volume distribution of a population as a histogram. The height of the vertical

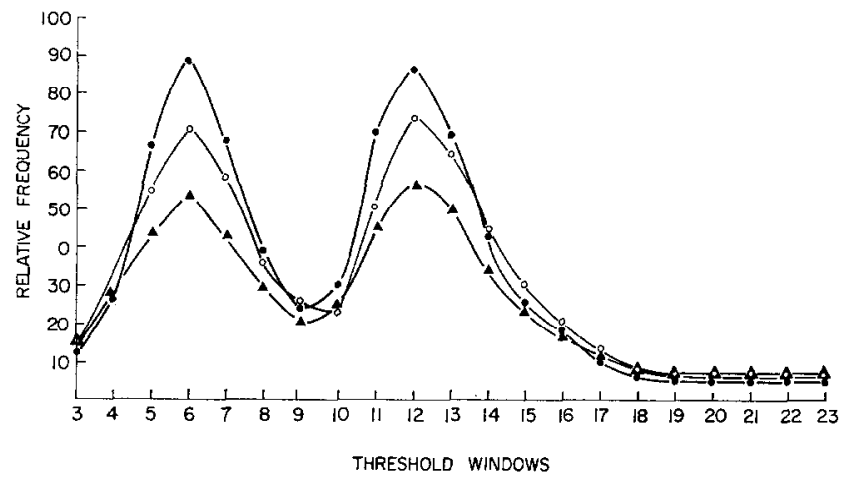

Fig. 3.-Effect of dilution on diploid and tetraploid distribution curve. Size distribution plots were performed on a sample with dilutions of $1 / 80,1 / 41$, and $1 / 21$ and representing coincidence ranging from 5-18\%. Individual curves were replotted and superimposed. Plotter amplification was adjusted to produce curves with similar heights; $\bullet \ldots . . .1 / 80$ dilution; $\bigcirc \_-0,1 / 41$ dilution; $\Delta-\Delta, 1 / 21$ dilution.

excursion ( $y$ axis) for each threshold window of four units is proportional to the number of nuclei whose pulse heights fall within that window.

Two factors influence the interpretation of the size distribution graphs. When two particles pass through the aperture simultaneously, the resulting coincident pulses will vary from twice the height and slightly more than equal the width of a single pulse, to equal the height but twice the width of a single pulse. This will skew the distribution curve to the right but will not shift its peak. The second factor is the presence or absence of a normal distribution curve for diploid and tetraploid nuclei. Falzone [8] isolated these two ploidy classes and established microscopically that each had a normal distribution curve in regard to mean diameter. The diploid population peaked at $5.0 \mu$ and the tetraploid nuclei at $8.0 \mu$ with only slight overlapping of their distribution curves.

In the present study, these factors were examined by diluting a sample of nuclei over a four-fold range, and plotting the resultant distribution curves over one another (Fig. 3). The calculated coincidence based on total instrument counts ranged from 5 to 18 per cent in these samples. The curves have approximately normal distributions. The skew to the right does not increase 
with increasing concentration in this range. Therefore, these effects were disregarded in calculating size distribution.

The Size Distribution Plotter does yield accurate information regarding the number of nuclei in each ploidy class as shown by DNA analysis. It was found that the DNA value for tetraploid nuclei was slightly greater than double that of the diploid nuclear DNA as was also noted by Falzone [8]. The diploid DNA values (6.49 and $7.16 \mu \mu \mathrm{g}$ DNA) are slightly lower than those reported by Thompson et al. [22] (6.7-7.2 $\mu \mu \mathrm{g} /$ nucleus of various rat organs excluding brain) but correspond well to values for rat brain (6.39 $\mu \mu \mathrm{g}$ DNA/nucleus) as previously reported [18].

Adult rat liver contains a high proportion of tetraploid nuclei [8] for which no physiological role has yet been established. One comparison of possible functional significance between diploid and tetraploid nuclei is the RNA/ DNA ratio. In 7 -month-old rats, this ratio is practically identical; whereas, in a 12 -month-old rat, the tetraploid nuclei have a slightly higher ratio than the diploid (Table II). Samis [17] recently confirmed that older rats have a lower amount of RNA in hepatic nuclei than do younger rats.

The technique described here appears readily applicable to the study of human neoplastic nuclei in which DNA and nuclear size are variables. The degree of accuracy obtained with electronic counting may allow biochemical nuclear studies to yield information now obtainable only with microscopic karyotyping techniques.

\section{SUMMARY}

1. A method of counting and sizing nuclei by an electronic particle counter is described and evaluated.

2. Nuclei are separated into diploid and tetraploid classes by continuous density gradient sedimentation and DNA and RNA values per nucleus are reported.

This work was supported in part by a grant from the University of Michigan Cancer Research Institute. I wish to express sincere gratitude to Dr B. W. Agranoff for stimulating discussion and advice concerning this investigation.

\section{REFERENCES}

1. Agranoff, B. W., Vallee, B. L. and Waugh, D. F., Blood J. Hematol. 9, 804 (1954).

2. Allen, J. D. and Guvaltis, A. V., Am. J. Clin. Pathol. 33, 553 (1960).

3. Berkson, J., Magath, T. B. and Hurn, M., Am. J. Physiol. 128, 309 (1940).

4. Brecher, G., Jakobek, E. F., Schneiderman, M. A., Williams, G. Z. and Schmidt, P. J., Ann. N.Y. Acad. Sci. 99, 242 (1962). 
5. Brecher, G., Schneiderman, M. and Williams, G. Z., Am. J. Clin. Pathol. 26, 1439 (1956).

6. Davis, G., Santen, R. J. and Agranoff, B. W., Anal. Biochem. 11, 153 (1965).

7. EAGLE, H., J. Exptl Med. 102, 595 (1955).

8. Falzone, J. A., Jr., Barrows, C. H. and Yiengst, M. J., Exptl Cell Res. 26, 552 (1962).

9. Goodman, H. S., Nature 193, 385 (1962).

10. Heller, I. H. and Elliot, K. A. C., Can. J. Biochem. Physiol. 32, 584 (1954).

11. KunitscheK, H. E., Nature 182, 234 (1958).

12. Lark, K. G. and Lark, C., Biochim. Biophys. Acta 43, 520 (1960).

13. Merchant, D. J., Kahn, R. H. and Murphy, W. H., Jr., Handbook of Cell and Organ Culture. Burgess Publishing Company, Minnesota, 1960.

14. Mattern, C. F. T., Brackett, F. S. and Olson, B. J., J. Appl. Physiol. 10 (1), 56 (1957).

15. Paul, J., Cell and Tissue Culture, 2nd ed. p. 281. E. and S. Livingstone, Edinburgh, 1960.

16. Richar, W. J. and Breakell, E. S., Am. J. Clin. Pathol. 31, 384 (1959).

17. Samis, H. W., Jr., WulfF, V. J. and Falzone, J. A., JR., Biochim. Biophys. Acta 91, 223 (1964).

18. Santen, R. J. and Agranoff, B. W., Biochim. Biophys. Acta 72, 251 (1963).

19. Segal, S. J. and Laurence, K. A., Ann. N.Y. Acad. Sci. 99, 271 (1962).

20. Sipe, C. R. and Cronkite, E. P., Ann, N. Y. Acad. Sci. 99, 262 (1962).

21. Sporn, M. B., Wanko, T. and Dingman, W. J., J. Cell Biol. 15, 109 (1962).

22. Thompson, R. Y., Heagy, F. C., Hutchison, W. C. and Davidson, J. N., Biochem. J. 53 460 (1953).

23. Treadwell, P. E. and Ross, J. D., Expll Cell Res. 29, 356 (1963). 